\title{
Performance Characteristics of Electric Vehicle Battery using Charging Station System with Grid-Connected Configuration via Matlab Simulation
}

\section{Tan Chong Chiat ${ }^{1}$, Khairul Anuar Mohamad ${ }^{1,2 *}$, Afishah Alias ${ }^{3}$, Mohd Shafiee Mohd Sanip ${ }^{4}$, Norisham Abdullah ${ }^{4}$, Mohammad Syahmi Nordin ${ }^{5}$}

${ }^{1}$ Faculty of Electrical and Electronic Engineering,

Universiti Tun Hussein Onn Malaysia, Parit Raja, 86400, Batu Pahat, Johor, MALAYSIA

${ }^{2}$ Microelectronic and Nanotechnology Shamsuddin Research Center,

Universiti Tun Hussein Onn Malaysia, Parit Raja, 86400, Batu Pahat, Johor, MALAYSIA

${ }^{3}$ Faculty of Applied Science and Technology,

Universiti Tun Hussein Onn Malaysia, Campus Pagoh, 84600, Pagoh, Johor, MALAYSIA

"Perisind Samudra Sendirian Berhad,Menara Zurich, Jalan Dato' Abdullah Tahir

80300 Johor Bahru, Johor, MALAYSIA

${ }^{5}$ School of Computer Science and Electronic Engineering,

University of Essex, Colchester CO4 3SQ, UNITED KINGDOM

*Corresponding Author

DOI: https://doi.org/10.30880/jeva.2021.02.02.002

Received 07 July 2021; Accepted 05 September 2021; Available online 30 December 2021

\begin{abstract}
Due to the increase in demand for electric vehicles (EV) in recent years, the lack of EV charging stations and different EVs' battery types are causing inconvenience to the user. The paper presents modeling and simulation of the grid-connected EV charging station system using MATLAB Simulink platform. The model consists of LCL filter, inverter, and battery charger. The inverter is regulated by a dq-frame that synchronizes with a phase-locked loop (PLL) to convert a three-phase alternating current (AC) source to a direct current (DC) source. Futhermore, lead acid (Pb-acid), lithium-ion (Li-ion), nickel-cadmium (Ni-Cd), and nickel metal hydride (Ni-MH) were tested and their performances were evaluated using the simulated EV charging station. All simulations were carried out and tested in the MATLAB Simulink platform. The results showed that Li-ion battery reaches the highest state-of-charge (SOC) value which is $51.66 \%$, Pb-acid is $51.60 \%$. Ni-MH is $51.55 \%$, and $\mathrm{Ni}-\mathrm{Cd}$ is $51.47 \%$ within $60 \mathrm{~s}$. The voltage values are $226.0 \mathrm{~V}, 225.2 \mathrm{~V}, 220.8 \mathrm{~V}$, and $220.2 \mathrm{~V}$ for Pb-acid, Ni-MH, Ni-Cd and Li-ion, respectively. The findings revealed that the lithium ion is the most suitable for the use of EV since it had the fastest charging and slowest to reach its maximum threshold value of charging voltage.
\end{abstract}

Keywords: Electric vehicle, grid-connected, charging station, $\mathrm{SOC}, \mathrm{Pb}$-acid, Li-ion, Ni-Cd, Ni-MH 


\section{Introduction}

Most of the vehicles nowadays still depend on gasoline or diesel fuel to power up the engine which will result in producing polluted gases such as carbon dioxide and nitrogen oxides. With the rise of awareness for environmental issues, electric vehicle (EV) which uses mainly on electricity, has been introduced in the mid-19th century to reduce the dependency on fuel [1]. Currently, battery capacity in a standard EV can last around an average of 200-300km travel distance after fully charged [2]. For the convenience of consumers to recharge their EV's battery, multiple EV charging stations are built in Malaysia. Currently, Malaysia recognized and accepted the standard International Electrotechnical Commission (IEC) 61851-1 in defining the condition for the charging station [3].

The demand for EVs in Malaysia has been on the rise and the amount listed EV charging stations has increased to 329 stations where 223 of them are at public locations [4]. While demand for EVs has picked up in recent years, concerns over the lack of charging stations and different EVs' battery types remain a drawback. An efficient charging station is a necessity to ensure that EV can continue operating on long-distance travel. This paper aims to design and simulate a grid-connected EV charging station in MATLAB Simulink. It also investigates the output voltage and current of the system and the SOC performance of lead acid, lithium-ion, nickel metal hydride, and nickel-cadmium batteries. The output obtained are compared and discussed to evaluate the performance of the charging system.

\section{Modelling}

The proposed design of grid connected EV charging station is shown in Fig. 1. It consists of inductor-capacitorinductor (LCL) filter, three-phase inverter, battery charger, inverter control system, and battery charger control system.

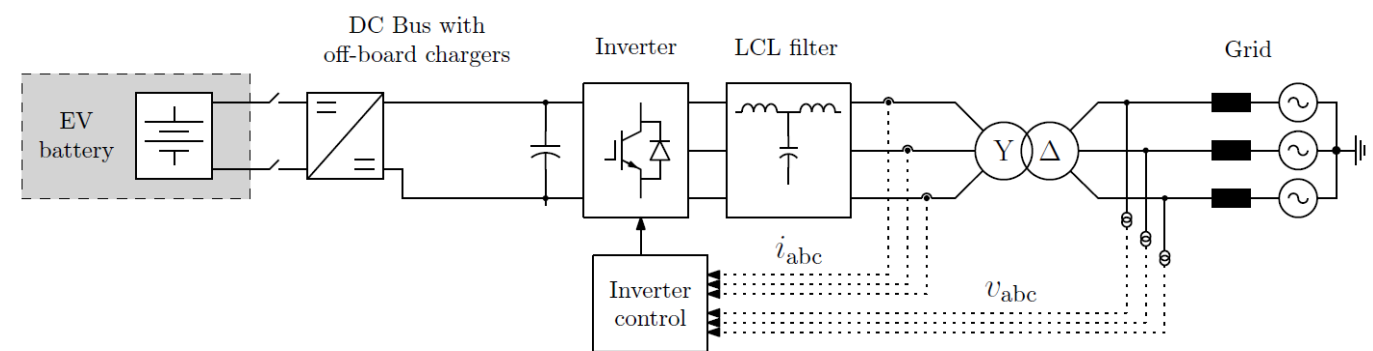

Fig. 1 - Proposed design of grid-connected EV charging station

\subsection{LCL Filter}

When loads are connected to the grid, it cause instability to the three-phase AC source of the distribution grid. Thus, to reduce the harmonic distortion of distribution grid power sources, passive LCL filter has been proposed as shown in Fig. 2, and the value of $\mathrm{C}_{\mathrm{f}}, \mathrm{L}_{1}$ and $\mathrm{L}_{2}$ are determined by using the following equation (1), (2), (3), and (4) [5]:

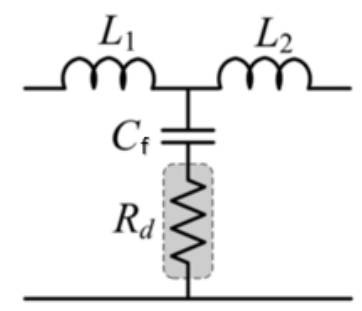

Fig. 2 - LCL Filter

$$
\begin{gathered}
C_{f}=\frac{0.05 \cdot P}{2 \pi \cdot f_{g} \cdot\left(V_{p h}\right)^{2}} \\
L_{1}=\frac{k_{a}+1}{k_{a} \cdot C_{f} \cdot\left(2 \pi \cdot f_{s w}\right)^{2}}
\end{gathered}
$$




$$
\begin{gathered}
\Delta I_{\text {max }}=\frac{\sqrt{2} \cdot P}{3 \cdot V_{p h}} \cdot 10 \% \\
L_{2}=\frac{V_{D C}}{6 \cdot f_{s w} \cdot \Delta I_{\text {max }}}
\end{gathered}
$$

where $P$ is rated active power, $f_{g}$ is grid frequency, $V_{p h}$ is effective phase voltage, $k_{a}$ is ripple attenuation factor, $f_{s w}$ is switching frequency and $\mathrm{V}_{\mathrm{DC}}$ is $\mathrm{DC}$ link voltage. The filter capacitor value, $\mathrm{C}_{\mathrm{f}}$ is limited by the reduction of the power factor which needs to be less than $5 \%$, the ripple attenuation factor is normally set at around $20 \%$ and the allowed fluctuate of rated current, $\Delta \mathrm{I}_{\max }$ is control within $10 \%$.

After obtaining the filter parameters, it is required to examine the resonance frequency using an equation (5) [5] within the range of less than half of the switching frequency, $f_{s w}$ and 10 times bigger than the grid frequency, $f_{g}$.

$$
f_{r e s}=\frac{1}{2 \pi} \cdot \sqrt{\frac{L_{1}+L_{2}}{L_{1} \cdot L_{2} \cdot C_{f}}}
$$

A damping resistor, $\mathrm{R}_{\mathrm{d}}$ connected with filter capacitor in series is required to prevent resonance and to reduce ripple at the switching frequency, $\mathrm{f}_{\mathrm{sw}}$. The value of the damping resistor is calculated using an equation (6) [5].

$$
R_{d}=\frac{1}{3 \cdot C_{f} \cdot 2 \pi \cdot f_{r e s}}
$$

\subsection{Three-Phase Inverter}

To supply a DC source to the EV charger, a three-phase inverter is designed as shown in Fig. 3, which is connected with the LCL filter. The three-phase inverter is a function to convert the three-phase AC source from the grid to the DC source. It is operated when receiving signal pulse width modulation (PWM) from the inverter control system. The charging station rated capacity, $S_{\text {rated }}$ was determined according to equation (7) [6], where cos $\varnothing$ is the power factor, $\mathrm{N}_{\text {slot }}$ is the amount of charging slots available for the individual charging station, and $\mathrm{k}_{\text {load }}$ is an overload factor for cover overloading in transients. A minimum value of DC capacitor, $\mathrm{C}_{\mathrm{DC}}$, as shown in equation (8) [6] is connected at the output of the inverter to support the DC current ripple, where $\mathrm{T}$ is the period of the AC voltage waveform, $\mathrm{n}$ is a multiple of $\mathrm{T}, \Delta \mathrm{r}$ is the DC power range of change during transients, and $\Delta \mathrm{x}$ is the allowable DC bus voltage range in change during transients.

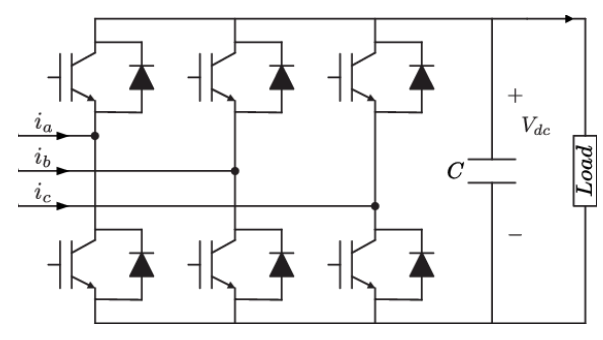

Fig. 3 - Three-phase Inverter

$$
\begin{gathered}
S_{\text {rated }}=\frac{k_{\text {load }} \cdot N_{\text {slot }} \cdot P}{\cos \emptyset} \\
C_{D C}=\frac{S_{\text {rated }} \cdot 2 n T \cdot \Delta r \cdot \cos \emptyset}{V_{D C}{ }^{2} \cdot \Delta x}
\end{gathered}
$$




\subsection{Battery Charger}

To charge the EV battery, a battery charger, as shown in Fig. 4, is required. It consists of two insulated gate bipolar transistor (IGBT) switches that controlled by control signals. This allows bi-directional power flows. When the lower IGBT switch is operating, it acts as a boost converter that amplifies the left side voltage supplied to the capacitor. When the upper IGBT switch is operating, it acts as a buck converter that the current is flows from the capacitor in opposite direction.

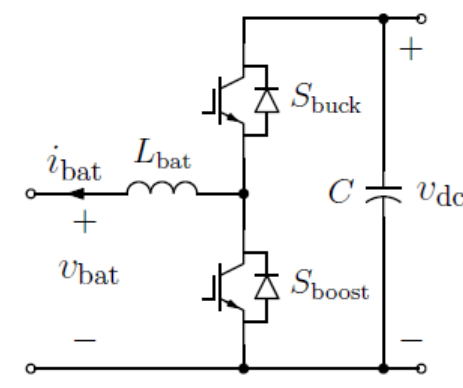

Fig. 4 - Battery Charger

\subsection{Inverter Control System}

The signal PWM that the inverter receiving is generated by the inverter control system. The system used a cascade dq-frame design which separates into two loops. The outer loop is controlled by voltage while the current controls the inner loop, as the block diagram is shown in Fig. 5. Synchronization with the grid voltage is performed through a phase-locked loop (PLL) as shown in Fig. 6. By using the grid voltage and current as input data, it is able to control the three-phase inverter to convert the three-phase source from the grid into reference DC voltage. The PLL is a function to generate output signal $\Theta_{\text {grid }}$ in order to use in the dq-frame inverter control.

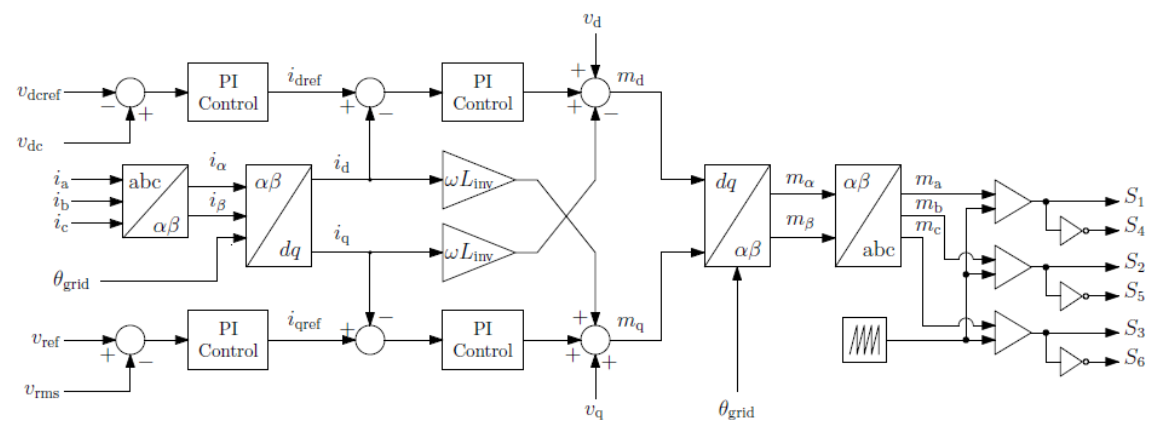

Fig. 5 - Inverter Control System in Block Diagram [6]

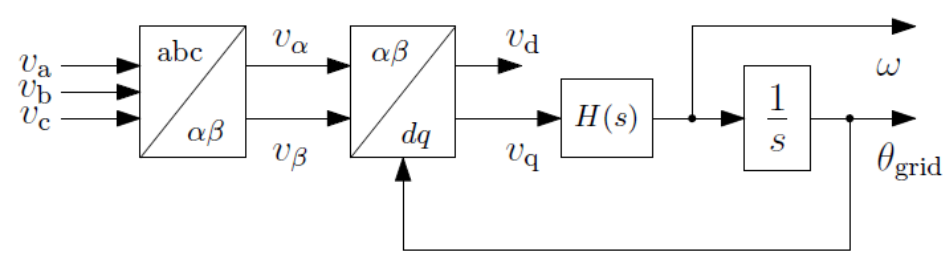

Fig. 6 - Phase-Locked Loop in Block Diagram [6]

\subsection{Inverter Control System}

The signals received by the IGBT switches in the battery charger are generated by the battery charger control system as shown in Fig. 7. By setting a reference current, the control system will generate a signal to IGBT switches in order to match the current supplies to the battery with the reference current. 


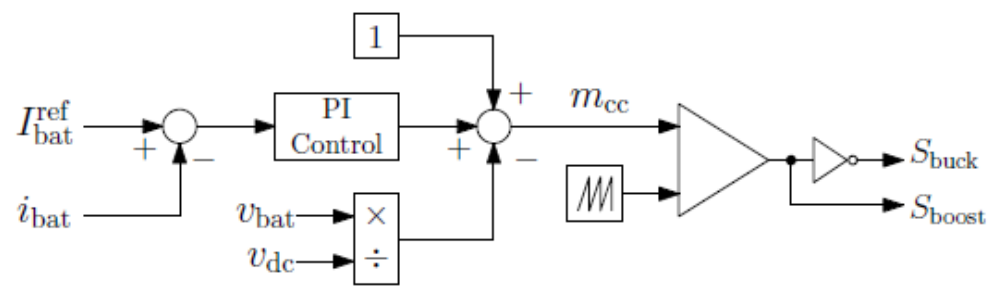

Fig. 7 - Battery Charger Control System in block diagram [6]

\subsection{EV Battery}

To test the operation of the designed EV charging station model, a battery is required to place at the output side of the model to simulate the charging process. Fig. 8 shows the electric circuit configuration of the battery model.

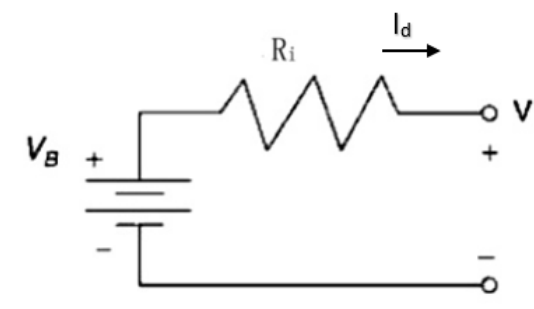

Fig. 8 - Thevenin equivalent circuit for a battery

\section{Results and Discussion}

The model of grid-connected EV charging station system is implemented using MATLAB Simulink package. Table 1 summarizes the major parameters of charging station for the simulation. The EV charging station, phase-locked loop, battery charger control system and inverter control system is shown in Fig. 9, Fig. 10, Fig. 11, and Fig. 12, respectively.

Table 1 - Parameter of charging station

\begin{tabular}{llll}
\hline Parameters & Values & Parameters & Values \\
\hline $\mathrm{P}$ & $100 \mathrm{~kW}$ & $\mathrm{C}_{\mathrm{f}}$ & $92.4 \mu \mathrm{F}$ \\
$\mathrm{f}_{\mathrm{g}}$ & $50 \mathrm{~Hz}$ & $\mathrm{~L}_{1}$ & $16.45 \mu \mathrm{H}$ \\
$\mathrm{V}_{\mathrm{ph}}$ & $415 \mathrm{~V}$ & $\mathrm{~L}_{2}$ & $1.174 \mathrm{mH}$ \\
$\mathrm{k}_{\mathrm{a}}$ & $20 \%$ & $\mathrm{f}_{\text {res }}$ & $4111 \mathrm{~Hz}$ \\
$\mathrm{f}_{\mathrm{sw}}$ & $10 \mathrm{kHz}$ & $\mathrm{R}_{\mathrm{d}}$ & $0.14 \Omega$ \\
$\mathrm{k}_{\text {load }}$ & 1.1 & $\cos \emptyset$ & 0.95 \\
$\mathrm{~N}_{\text {slot }}$ & 1 & $\mathrm{~S}_{\text {rated }}$ & $120 \mathrm{kVA}$ \\
$\mathrm{n}$ & 0.5 & $\mathrm{~T}$ & $1 / 50 \mathrm{~s}$ \\
$\Delta \mathrm{r}$ & $10 \%$ & $\Delta \mathrm{x}$ & $20 \%$ \\
$\mathrm{~V}_{\mathrm{DC}}$ & $800 \mathrm{~V}$ & $\mathrm{C}_{\mathrm{DC}}$ & $3.5 \mathrm{mF}$ \\
Initial SOC & $50 \%$ & I & $150 \mathrm{~A}$ \\
Nominge & & Rated & $150 \mathrm{Ah}$ \\
Battery & $200 \mathrm{~V}$ & capacity & \\
Voltage & & & \\
\hline
\end{tabular}




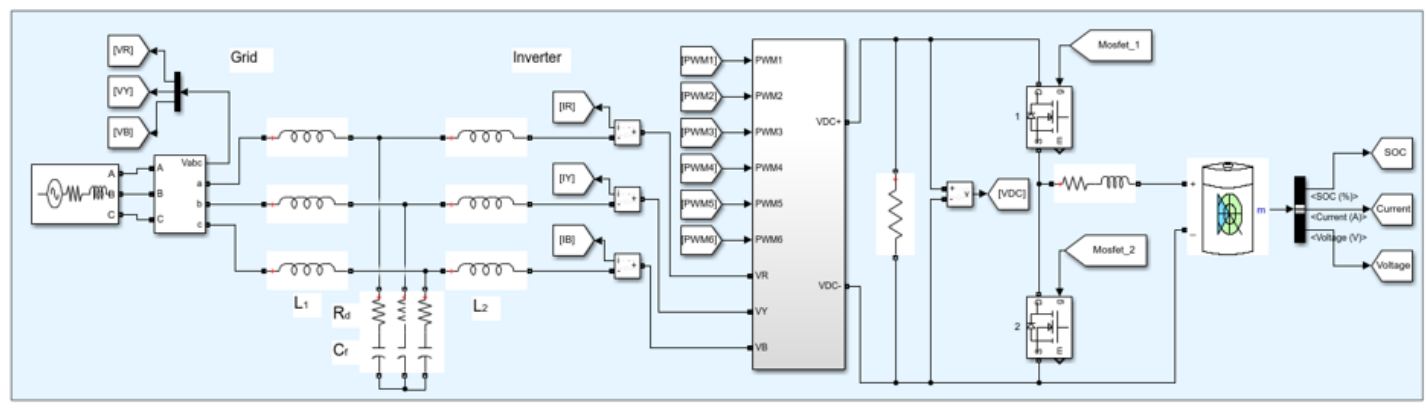

Fig. 9 - The EV charging station in MATLAB Simulink

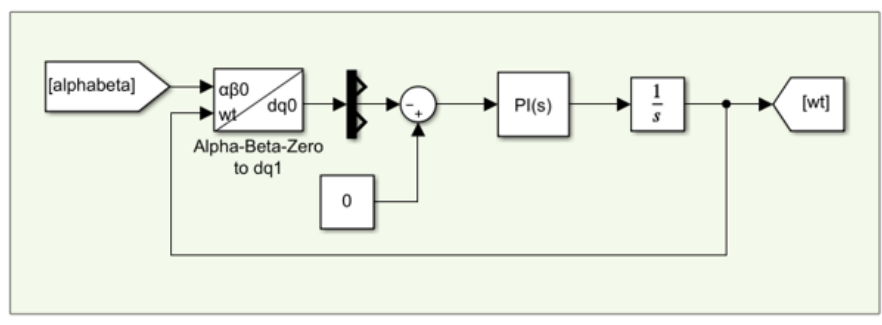

Fig. 10 - The Phase-Locked Loop in MATLAB Simulink

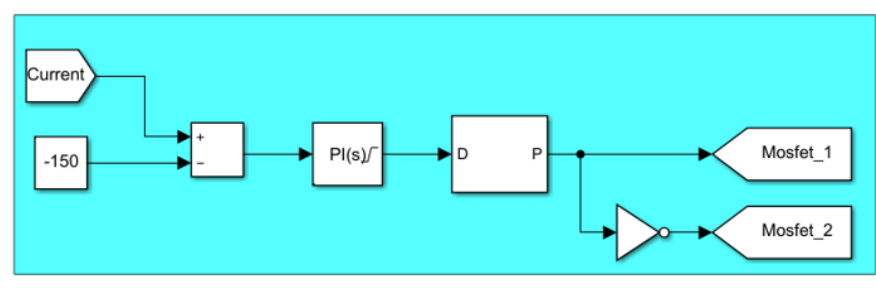

Fig. 11 - Battery charger control system in MATLAB Simulink

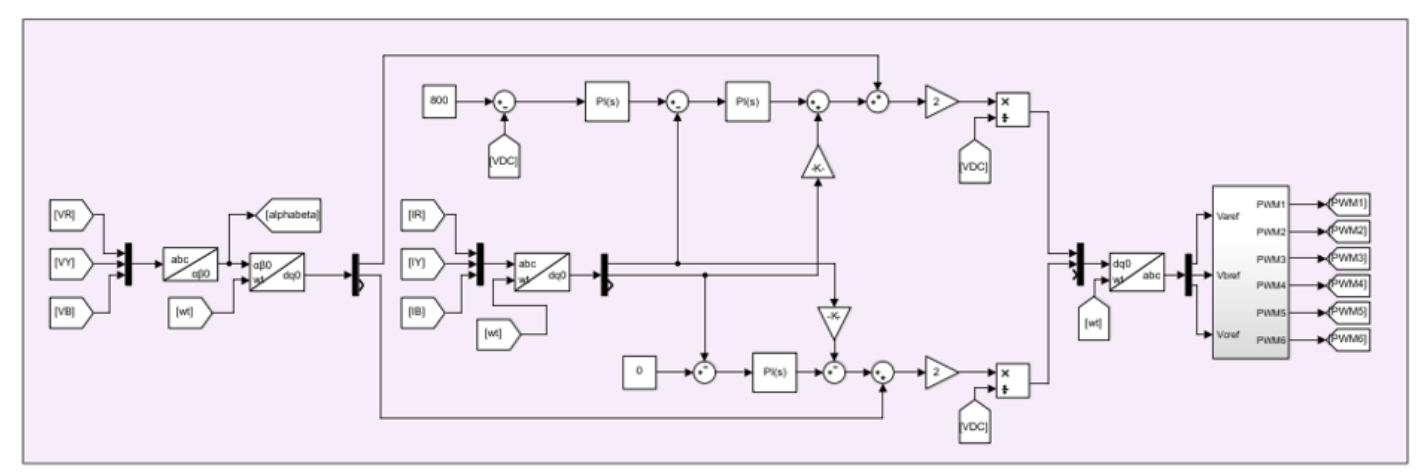

Fig. 12 - Inverter control system in MATLAB Simulink

\subsection{Simulation of EV Charging System with Grid-Connected Configuration}

In Fig. 13(a) and Fig. 13(b), it shows that the three-phase AC voltage and current were under a steady-state during the simulation. The rms voltage of each phase was maintained at $415 \mathrm{~V}$ while the rms current of each phase was maintained at 162A. The total harmonic distortion (THD) in the simulation model was 1.13\%, as shown in Fig. 14 . Meanwhile, Fig. 15 shows the output of DC voltage converted from a three-phase AC source. The rise time was $7.0 \mathrm{~ms}$ for the output DC voltage to reach $800 \mathrm{~V}$ for the first time. The DC voltage reached the highest output which was $1259 \mathrm{~V}$ at the peak time of $10.6 \mathrm{~ms}$. For the output to achieve stable and constant $800 \mathrm{~V}$, it took a settling time of $0.036 \mathrm{~s}$. 

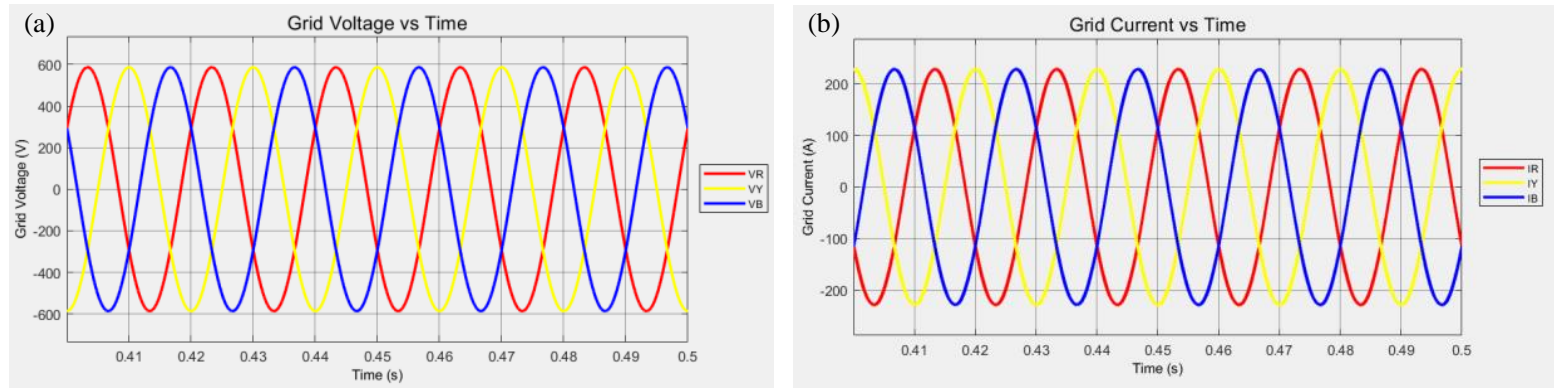

Fig. 13 - (a) Grid voltage against time; (b) Grid current against time

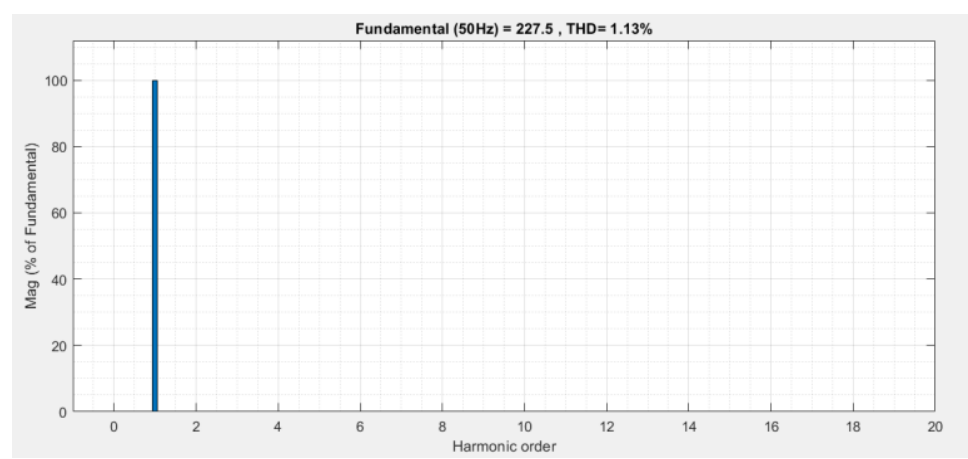

Fig. 14 - Magnitude against Harmonic Order

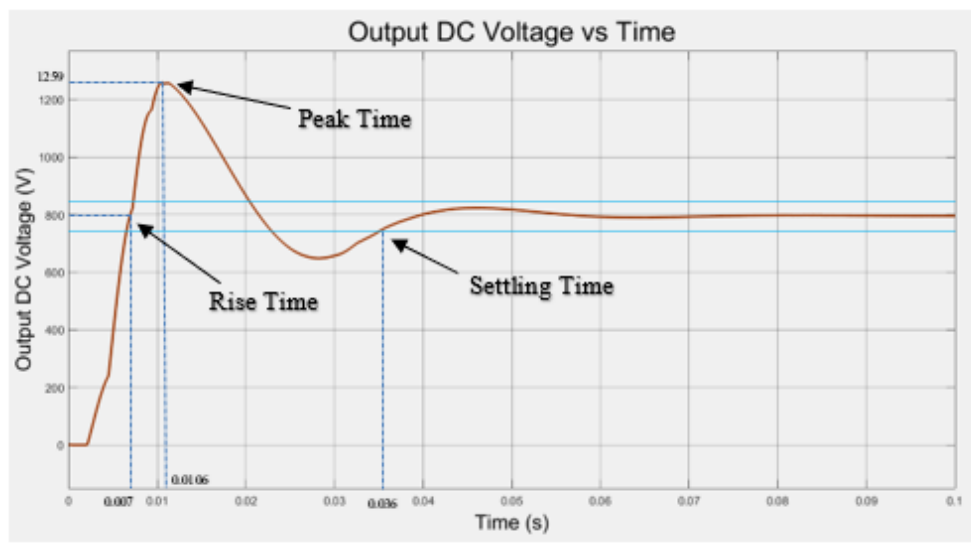

Fig. 15 - Output DC voltage against Time

\subsection{Performance Characteristic of EV Battery}

A lead-acid (Pb-acid), lithium-ion (Li-ion), nickel-cadmium (Ni-Cd) and nickel-metal hydride (Ni-MH) are EV batteries used to investigate the load performance of the simulated charging station system. The characteristics of voltage, current and state-of-charge (SOC) against the time of four EV batteries are shown in Fig. 16, Fig. 17, and Fig. 18 , respectively. The time taken for simulation was set at 60 s. 

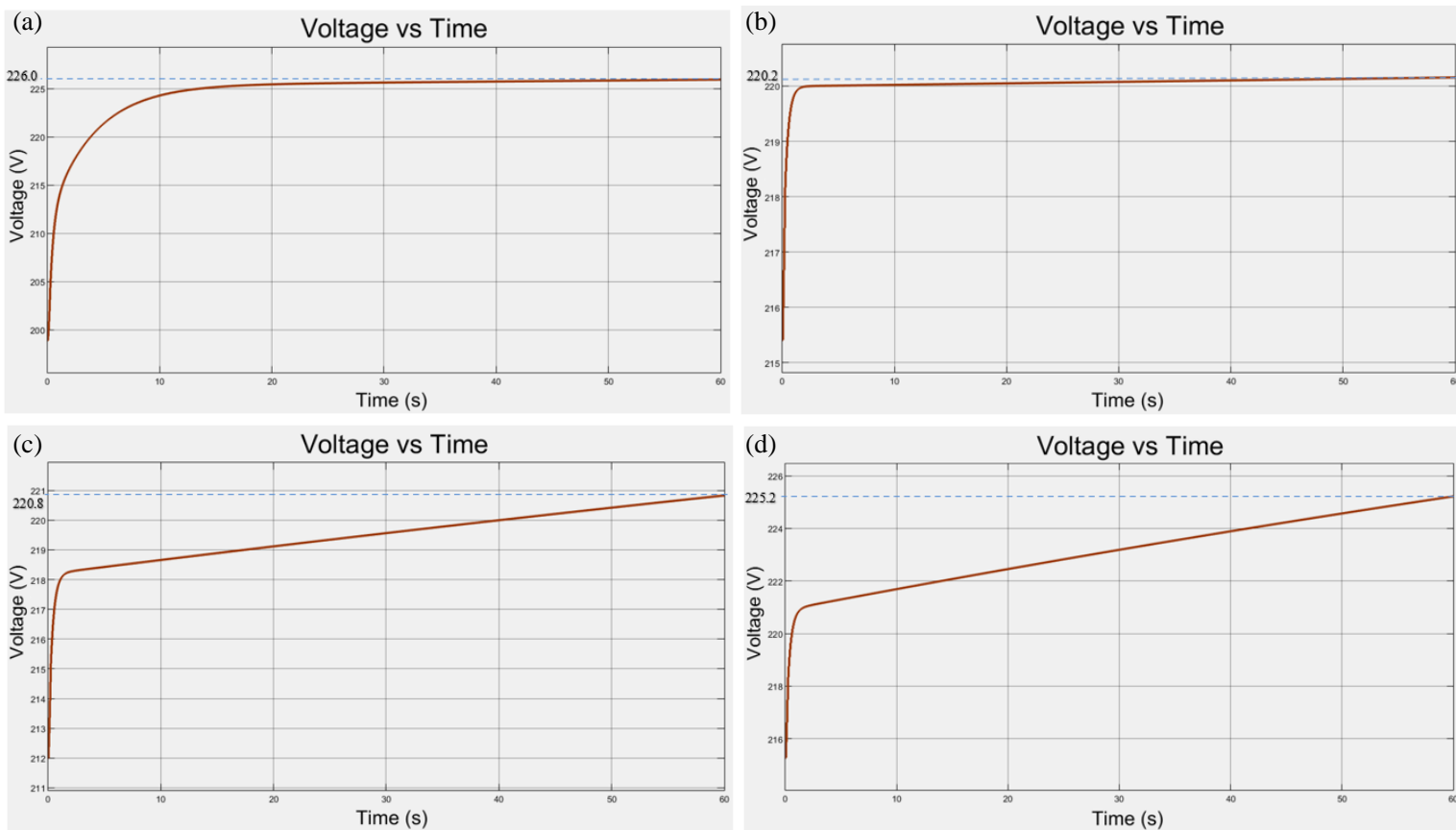

Fig. 16 - Voltage against Time: (a) Lead Acid; (b) Lithium-ion; (c) Nickel-Cadmium; (d) Nickel Metal Hydride
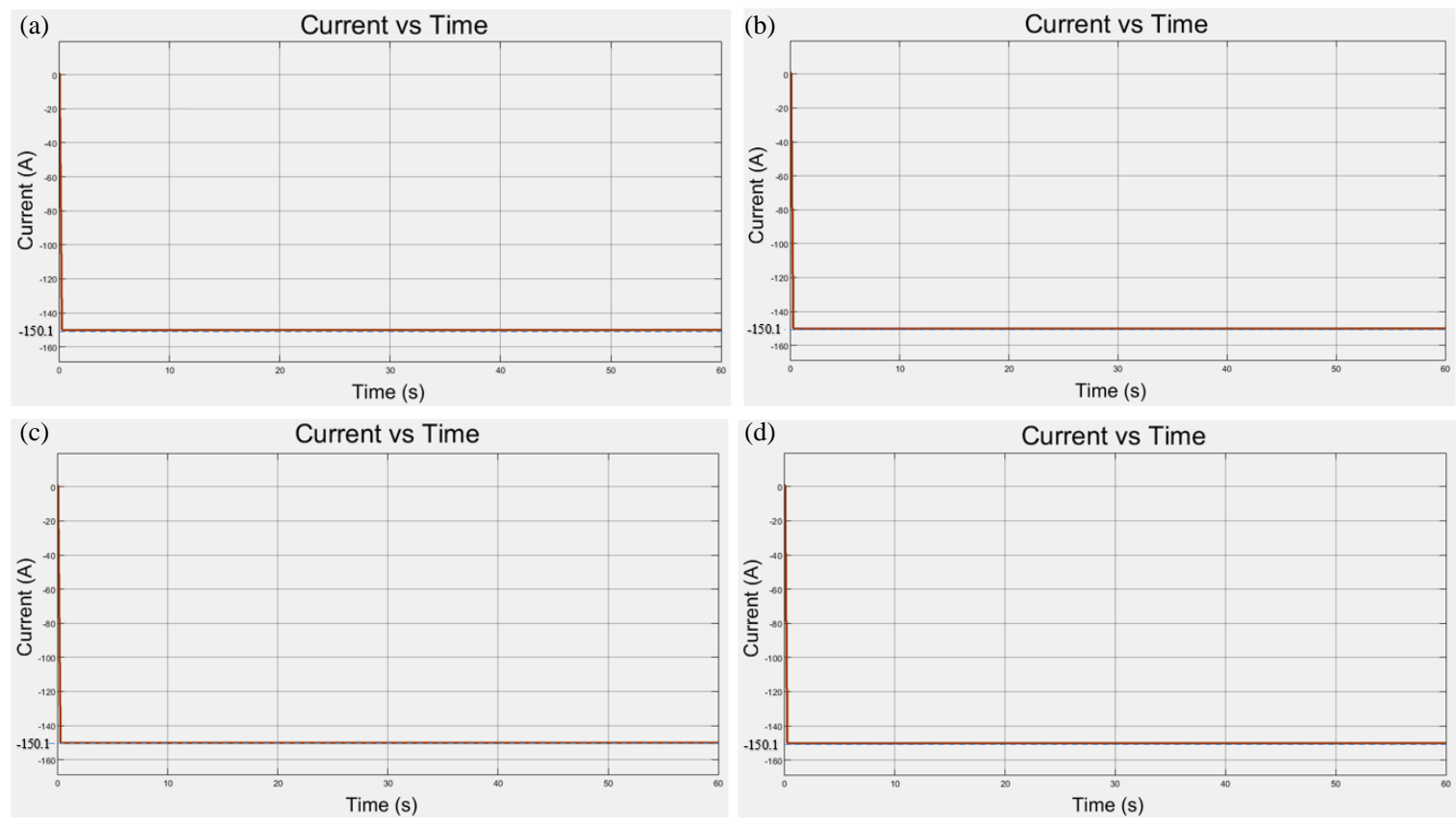

Fig. 17 - Current against Time: (a) Lead Acid; (b) Lithium-ion; (c) Nickel-Cadmium; (d) Nickel Metal Hydride 
(a)

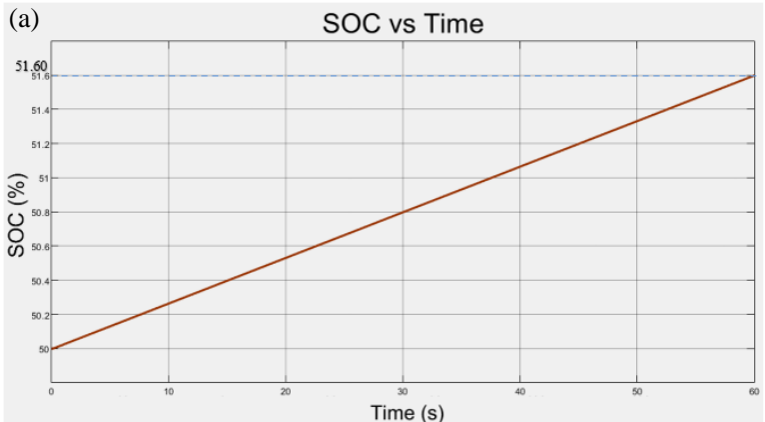

(c)

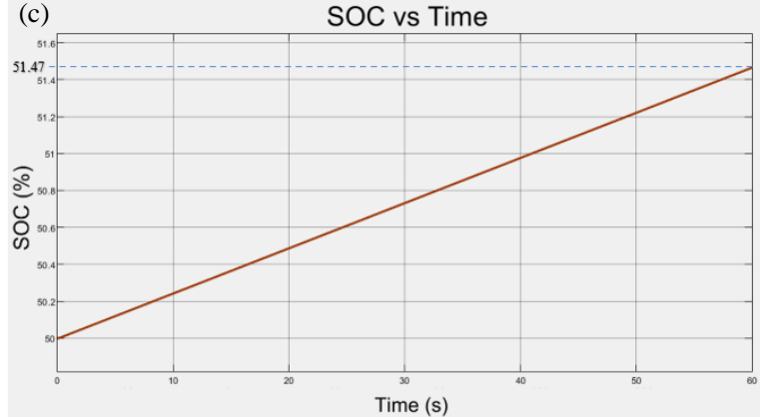

(b)

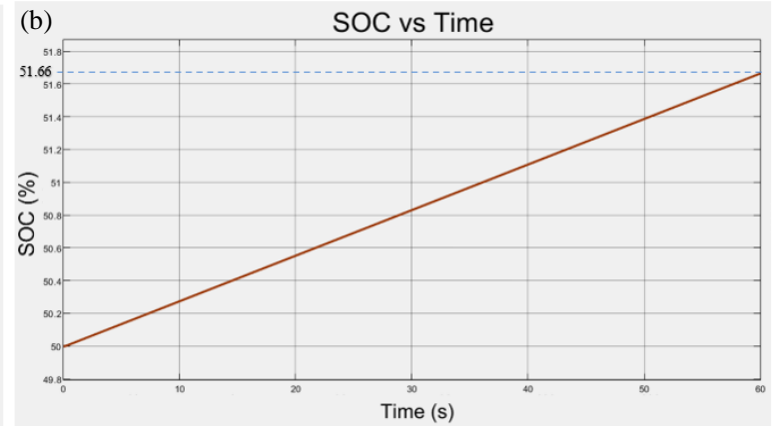

(d)

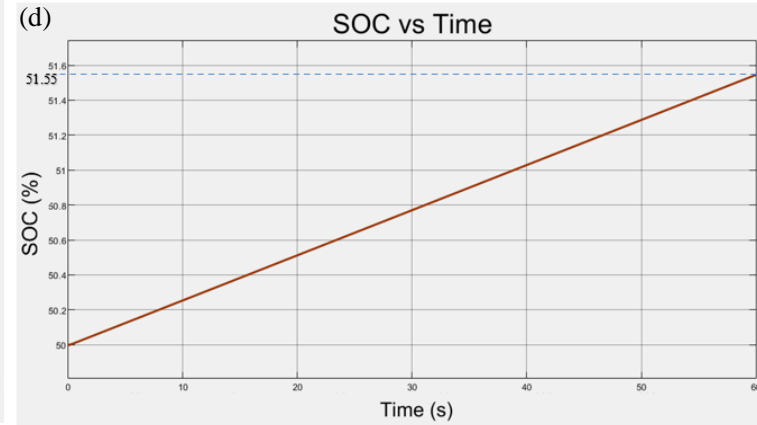

Fig. 18 - SOC against Time: (a) Lead Acid; (b) Lithium-ion; (c) Nickel-Cadmium; (d) Nickel Metal Hydride

Table 2 summarizes the performance characteristics comparison for EV batteries. The comparison indicates that the results obtained were unalike even though the battery capacity and nominal voltage were identical for the four batteries. The voltage of the Pb-acid battery reached the highest value which was $226.0 \mathrm{~V}$ at the end of the simulation. Therefore, the $\mathrm{Pb}$-acid battery was the fastest battery to change to the constant voltage charging method when it reached the maximum threshold value of charging voltage compared to the other three batteries. On the contrary, the voltage of Li-ion had the lowest value that was $220.2 \mathrm{~V}$. In terms of current, four of the batteries reached the reference current value that was $-150 \mathrm{~A}$ which was according to the constant current charging method. However, the Li-ion battery reached $51.66 \%$ of SOC value that was the highest among the batteries while the Ni-Cd battery had the lowest value of $51.47 \%$.

Table 2 - Performance characteristics comparison

\begin{tabular}{|c|c|c|c|c|}
\hline Performance Characteristics & Pb-Acid & Li-ion & Ni-Cd & Ni-MH \\
\hline Battery Capacity (Ah) & 150 & 150 & 150 & 150 \\
\hline Nominal Voltage (V) & 200 & 200 & 200 & 200 \\
\hline Initial SOC (\%) & 50 & 50 & 50 & 50 \\
\hline $\begin{array}{l}\text { Voltage of Battery after } 60 \text { s of } \\
\text { simulation }(V)\end{array}$ & 226.0 & 220.2 & 220.8 & 225.2 \\
\hline $\begin{array}{l}\text { Current of Battery after } 60 \text { s of } \\
\text { simulation (A) }\end{array}$ & -150.1 & -150.1 & -150.1 & -150.1 \\
\hline $\begin{array}{l}\text { SOC of Battery after } 60 \text { s of } \\
\text { simulation }(\%)\end{array}$ & 51.60 & 51.66 & 51.47 & 51.55 \\
\hline
\end{tabular}

\section{Conclusion}

The model designed was able to maintain the rms voltage of each phase at $415 \mathrm{~V}$ and the rms current of each phase at $162 \mathrm{~A}$ while the total harmonic distortion (THD) displayed in the model was $1.13 \%$. Besides, a stable DC voltage of $800 \mathrm{~V}$ was constantly generated from the inverter after $7.0 \mathrm{~ms}$ of simulation. In comparing the performance characteristics between the four types of $\mathrm{Pb}$-Acid, Li-ion, $\mathrm{Ni}-\mathrm{Cd}$, and $\mathrm{Ni}-\mathrm{MH}$ batteries, the results show that the Li-ion reached $51.66 \%$ SOC within the 60 s of charging time which was the highest value compared to the other three batteries. However, the Li-ion had the lowest voltage value among four batteries, indicating that it requires the slowest time to charge up to the maximum threshold value of charging voltage. Therefore, when the constant-current constantvoltage charging method applies to the system, the Li-ion will be charging under constant-current for the longest time 
compared to the other three batteries before switching to the constant-voltage charging that will lower the current supply to the battery. Thus, Li-ion is the most suitable battery to choose for the use of EV among four types of batteries in terms of their charging speed. Apart from that, further research on the grid-connected EV charging station model with more slots is needed for charging multiple batteries simultaneously.

\section{Acknowledgement}

This research was made possible by funding from Internal Research Grant (TIER1) number H066 provided by the Universiti Tun Hussein Onn Malaysia. The authors would also like to thank the Faculty of Electrical and Electronic Engineering, Universiti Tun Hussein Onn Malaysia for its support.

\section{References}

[1] Vepachedu, S. (2017). The History of the Electric Car. Andhra Journal of Industrial News, 14-27

[2] Vidyanandan, K.V. (2019). Batteries for Electric Vehicles. A House e-Journal of Corporate Planning, NTPC Ltd., $1(38)$

[3] Rata, M., et al. (2019). The ElectricalVehicle Simulator for Charging Station in Mode 3 of IEC 61851-1 Standard. Energies, 13(1), 176.

[4] Elma, O. (2020). A dynamic charging strategy with hybrid fast charging station for electric vehicles. Energy, 202, 117680

[5] Ben Saïd-Romdhane, M., Naouar, M. W., Belkhodja, I. S., and Monmasson, E. (2016). Simple and systematic LCL filter design for three-phase grid-connected power converters. Mathematics and Computers in Simulation, 130, 181-193

[6] Arancibia, A., and Strunz, K. (2012). Modeling of an electric vehicle charging station for fast DC charging. 2012 IEEE International Electric Vehicle Conference, 1-6 